\title{
Evaluation on Transfer Reliability of Wuhan Comprehensive Transport Hub Based on Fuzzy Comprehensive Evaluation
}

\author{
Hao Zhang ${ }^{1, a}$, Xifu Wang ${ }^{2, b}$ \\ ${ }^{1}$ School of Traffic and Transportation, Beijing Jiaotong University, 100044, China \\ ${ }^{2}$ School of Traffic and Transportation, Xifu Wang, Beijing Jiaotong University, 100044, China \\ a14120922@bjtu.edu.cn, ${ }^{b}$ wxfky@vip.sina.com
}

\begin{abstract}
Key Words: Comprehensive transport hub; Reliability Evaluation; Fuzzy Comprehensive Evaluation

ABSTRACT:Urban Comprehensive transport hub transfer system is an important part of urban public transport network. It's functionality and high level of service is not only the needs of urban modernization, but also one of the important means to attract travelers to use public transportation to ease road congestion. The evaluation of traffic transfer system will help city managers recognize the weaknesses in city traffic and make the appropriate improvements.

In this paper, we mainly discussed the urban public transportation transfer, defined the definition of reliability, and analyzed composition and the factors influence its reliability. Before analyze the public transportation transfer in Wuhan city, it's important to statistics which Urban transport hubs are involved. After that, we should build an evaluation system. Then, according to the evaluation system, we collected the relevant data and analyzed them. Finally, through Fuzzy Comprehensive Evaluation, we will get the evaluation result.
\end{abstract}

\section{Introduction}

In the city that public transport is the main mode of transportation, comprehensive transport hub is an important node of public transportation network. It provides the transfer and combinations of traveling ways, distribution travelers. The main function of comprehensive transport hub including the following two aspects ${ }^{[1]}$.

(1)The convergence function of traffic point.

Depending on the residents travel requirements linked different lines, different means of transportation as an integral.

(2)The passenger distribution function of plane.

Comprehensive transport hub taking advantage of other hub station systems and bus lines connected thereto, to expansion the function from point to the plane.

In addition, transit hub are dense regions of urban land development and using, therefore, the city transport hubs have a positive promoting to urban transport network functions.

According to comprehensive transportation hubs' location and functions, we can Analyzed from different angles like traffic functions, the combination of transportation modes, service areas and layout forms ${ }^{[2]}$. The transport hub types divided by functions is shown as following Table 1. 
Table 1. Transport hub types divided by functions

\begin{tabular}{|cc|}
\hline Functions & Types \\
\hline Traffic functions & $\begin{array}{c}\text { Outbound transportation hub, urban public } \\
\text { transportation hub }\end{array}$ \\
The combination of & Line transfer hub, means transfer hub, \\
transportation modes & compound hub \\
service areas & Urban area class hub, downtown aera class \\
layout forms & hub, district area class hub \\
& Grade separation hub, plane hub \\
\hline
\end{tabular}

\section{Analysis of the Meaning of Comprehensive Transport hub Transfer Reliability}

Reliability refers to the ability of the system to complete its intended function within a certain time and a predetermined condition.

There are not lot to use reliability as a index in traffic area, neither a specific definition nor measure methods. There are two main methods to measure systems reliability: One is on the angel of users, in this way, the reliability of the system is defined by the user's sensory understanding of the system's reliability. The other way need to analysis the system's components. Through the reliability of these elements or units to get the system's reliability ${ }^{[3]}$.

For the feature of comprehensive transportation hub, The second method can be used to define the reliability of Wuhan comprehensive transportation hub reliability, the analysis object including Inter-city bus station, railway station and airport.

\section{The Establish of Evaluation System}

With the analysis of table 1, the involved comprehensive transport hub are: 12 inter-city bus station, three railway stations and an airport in Wuhan. The railway station and airport are Wuchang Railway Station, Hankou Railway Station, Wuhan Railway Station and Tianhe Airport.

There are two kinds of transport hub transfer reliability, one is under normal condition, the other is under abnormal condition. Under the normal condition, the reliability analysis is mainly about the daily traffic. Under the abnormal condition, the reliability analysis could be divided by disaster, abnormal weather and abnormal traffic events. For different conditions, travelers have different expectations for traffic, and produce different evaluations ${ }^{[4]}$. The classify of comprehensive transport hub transfer reliability is as following Fig 1.

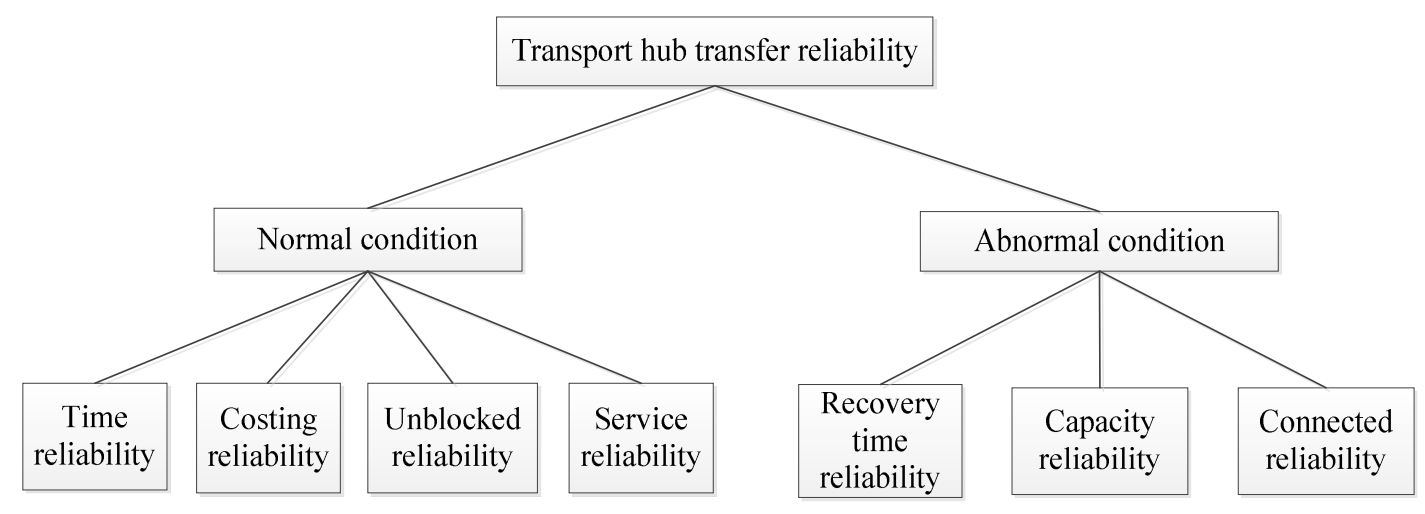

Fig 1 . The classify of comprehensive transport hub transfer reliability

For the reason that abnormal conditions have strong attributions of bursting an and random, so it's 
very hard to prediction accurately. This paper discuss the state of road network under normal condition only. The evaluation index and parameters as following Fig 2.

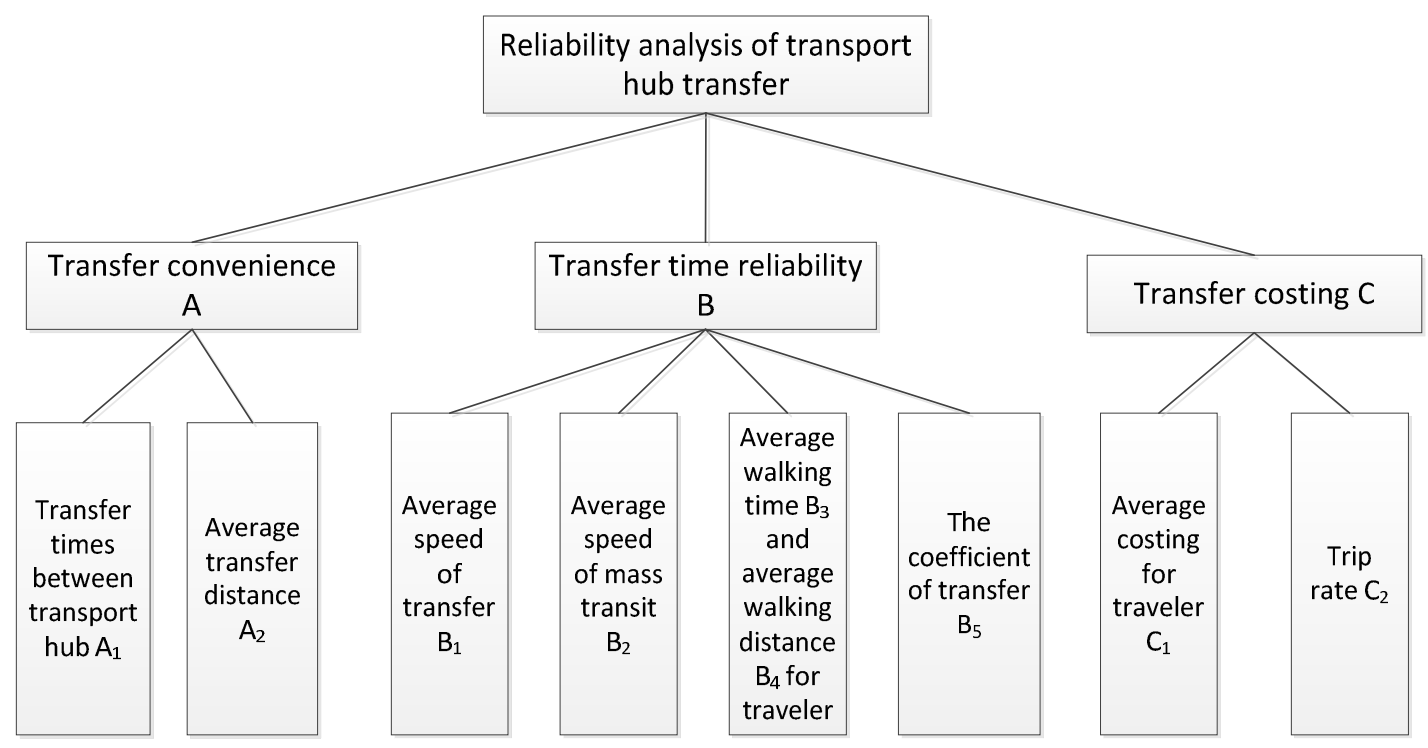

Fig 2. Reliability analysis of transport hub transfer

Because of the attribution of the analysis of comprehensive transport hub reliability, it's suitable to use fuzzy comprehensive evaluation method. Fuzzy comprehensive evaluation method is a method to deal with mathematical models which cannot be described by precisely mathematical. It is based on fuzzy mathematics, and use the theory of composition of fuzzy relation, to quantitative the factors which boundary is not clear and not easy to qualified precisely.

Fuzzy comprehensive evaluation is the application of the principle of fuzzy transform and the maximum membership degree principle, considering various factors and the evaluated matters, the evaluate it comprehensively. The mathematical model of this method is ${ }^{[5]}$ : Determining the evaluation factors set $\mathrm{F}$, evaluation set $\mathrm{V}$, membership degree $\mathrm{Yi}$. In the end, weight vector and judgment matrix multiple, and the result is the final evaluation. The equation of this model are as follow.

$$
B=W \cdot R=\left(W_{1}, W_{2}, \ldots, W_{m}\right)\left[\begin{array}{ccc}
r_{11} & \ldots & r_{1 n} \\
\ldots & & \ldots \\
r_{n 1} & \ldots & r_{n n}
\end{array}\right]=\left(b_{1}, b_{2}, \ldots, b_{n}\right)
$$

\section{COMPUTATION PROCESS AND CONCLUSION}

The first step of fuzzy comprehensive evaluation method is to establish evaluation set V. And there are five remarks in the evaluation set, the detail are as follows:

$\mathrm{V}=(\mathrm{v} 1, \mathrm{v} 2, \mathrm{v} 3, \mathrm{v} 4, \mathrm{v} 5)=\{$ very good, good, normal, not good, bad $\}$

The second step is to determine weight. After discussed with teacher and referenced other documents, the weights are as follows.

$$
\begin{aligned}
& \mathrm{U}=(0.2,0.4,0.4) \\
& \mathrm{U}_{1}=(0.6,0.4) \\
& \mathrm{U}_{2}=(0.3,0.2,0.15,0.15,0.2) \\
& \mathrm{U}_{3}=(0.45,0.55)
\end{aligned}
$$

The parameters are classified as following classification tables. 
Table 2. Transfer time classification table

\begin{tabular}{|llllll|}
\hline Evaluation grade & Very good & Good & Normal & Not good & Bad \\
\hline Transfer time & $<1$ & {$[1,2)$} & 2 & $(3,4]$ & $>4$ \\
\hline
\end{tabular}

Table 3. Transfer distance classification table $[\mathrm{km}]$

\begin{tabular}{|lccccc|}
\hline Evaluation grade & Very good & Good & Normal & Not good & Bad \\
\hline Transfer distance & $<6$ & {$[6,12)$} & {$[12,20)$} & {$[20,28)$} & $\geq 28$ \\
\hline
\end{tabular}

Table 4. Speed of transfer classification table $[\mathrm{km} / \mathrm{h}]$

\begin{tabular}{|cccccc|}
\hline Evaluation grade & Very good & Good & Normal & Not good & Bad \\
\hline Speed of transfer & $>25$ & {$[16,25)$} & {$[13,16)$} & {$[10,13)$} & $\leq 10$ \\
\hline
\end{tabular}

Table 5. Speed of mass transit classification tanle $[\mathrm{km} / \mathrm{h}]$

\begin{tabular}{|cccccc|}
\hline Evaluation grade & Very good & Good & Normal & Not good & Bad \\
\hline Speed of mass transit & $>22$ & {$[22,17)$} & {$[17,13)$} & {$[13,9)$} & $\leq 9$ \\
\hline
\end{tabular}

Table 6. Average walking distance for traveler [m]

\begin{tabular}{|cccccc|}
\hline Evaluation grade & Very good & Good & Normal & Not good & Bad \\
\hline Average walking distance & $<300$ & {$[300,450)$} & {$[450,650)$} & {$[650,900)$} & $\geq 900$ \\
\hline
\end{tabular}

Table 7. Average walking time for traveler [Minute]

\begin{tabular}{|cccccc|}
\hline Evaluation grade & Very good & Good & Normal & Not good & Bad \\
\hline Average walking time & $<3$ & {$[3,6)$} & {$[6,9)$} & {$[9,12)$} & $\geq 12$ \\
\hline
\end{tabular}

Table 8 . The coefficient of transfer classification table

\begin{tabular}{|cccccc|}
\hline $\begin{array}{c}\text { Evaluation } \\
\text { grade }\end{array}$ & Very good & Good & Normal & Not good & Bad \\
\hline $\begin{array}{c}\text { coefficient of } \\
\text { transfer }\end{array}$ & $<1.3$ & {$[1.3,1.5)$} & {$[1.5,1.7)$} & {$[1.7,1.9)$} & $\geq 1.9$ \\
\hline
\end{tabular}

Table 9. Average costing for traveler [Yuan]

\begin{tabular}{|cccccc|}
\hline Evaluation grade & Very good & Good & Normal & Not good & Bad \\
\hline costing & $<2$ & $(2,5]$ & $(5,7]$ & $(7,9]$ & $>9$ \\
\hline
\end{tabular}

Table 10. Trip rate classification table

\begin{tabular}{|cccccc|}
\hline Evaluation grade & Very good & Good & Normal & Not good & Bad \\
\hline Trip rate & $(0.8,1.1]$ & $(1.1,1.4]$ & $(1.4,1.7]$ & $(1.7,2.0]$ & others \\
\hline
\end{tabular}

According to the classification tables above, the result of single factor evaluation are as follows. 
Table 11. Result of single factor evaluation

\begin{tabular}{cccccc}
\hline Ranks & Very good & Good & Normal & Not good & Bad \\
\hline $\mathrm{A}_{1}$ & 1 & 0 & 0 & 0 & 0 \\
$\mathrm{~A}_{2}$ & 0 & 0 & 1 & 0 & 0 \\
$\mathrm{~B}_{1}$ & 0 & 0 & 1 & 0 & 0 \\
$\mathrm{~B}_{2}$ & 0 & 1 & 0 & 0 & 0 \\
$\mathrm{~B}_{3}$ & 0 & 0 & 1 & 0 & 0 \\
$\mathrm{~B}_{4}$ & 0 & 0 & 1 & 0 & 0 \\
$\mathrm{~B}_{5}$ & 0 & 1 & 0 & 0 & 0 \\
$\mathrm{C}_{1}$ & 0 & 0 & 1 & 0 & 0 \\
$\mathrm{C}_{2}$ & 0 & 1 & 0 & 0 & 0 \\
\hline
\end{tabular}

Based on the results above:

$$
R_{1}=\left[\begin{array}{lllll}
1 & 0 & 0 & 0 & 0 \\
0 & 0 & 1 & 0 & 0
\end{array}\right], \quad R_{2}=\left[\begin{array}{lllll}
0 & 0 & 1 & 0 & 0 \\
0 & 1 & 0 & 0 & 0 \\
0 & 0 & 1 & 0 & 0 \\
0 & 0 & 1 & 0 & 0 \\
0 & 1 & 0 & 0 & 0
\end{array}\right], R_{3}=\left[\begin{array}{lllll}
0 & 0 & 1 & 0 & 0 \\
0 & 1 & 0 & 0 & 0
\end{array}\right]
$$

Because of $U_{1}=(0.6,0.4)$, the evaluation vector of transfer convenience is as follow:

$\mathrm{Y}_{1}=\mathrm{U}_{1} \cdot \mathrm{R}_{1}=(0.6,0,0.4,0,0)$

According to the principle of maximum degree of membership, the result 0.6 means that the remark of transfer convenience is good.

Simultaneously, $\mathrm{Y}_{2}=\mathrm{U}_{2} \cdot \mathrm{R}_{2}=(0,0.4,0.6,0,0), \mathrm{Y}_{3}=\mathrm{U}_{3} \cdot \mathrm{R}_{3}=(0,0.55,0.45,0,0)$. So the remark of transfer time reliability is good and the remark of transfer costing is normal.

Finally, by $U=(0.2,0.4,0.4)$, the evaluation vector of transfer convenience is as follows:

$\mathrm{Y}=\mathrm{U} \cdot \mathrm{R}=(0.12,0.38,0.5,0,0)$

According to the principle of maximum degree of membership, the result 0.5 means that the remark of Wuhan transport hub reliability is normal.

\section{References}

[1] Ailian Zhou. Planning and Design of Traffic Hub[M]. China Communication Public, 2013.

[2] Haichao Wang, Guoren Xie, Shuhua Dang. Reliability Analysis of City Road Networl[J]. Journal of Hebei Institute of Architectural Science, 1997, 14(3): 17-21.

[3] Lili Yang, Study on Transfer System Reliability Measurement of Comprehensive Passenger Transport Terminal[D]. Changchun: Jilin University, 2012.

[4] Xiaoming Liu, Longli Shen, Xiaokuan yang. Research On Comprehensive Evaluation Index System of City Passenger Transport Hub[J]. China Journal of Highway And Transport, 1995, 8(1): 97-102.

[5] Jian Ji, Ping Cheng. The Method of Fuzzy Mathematics And Its Application[M]. Huazhong University of Science of Technology Press, 2000. 